„Kwartalnik Filmowy” nr 116 (2021)

ISSN: 0452-9502 (Print) ISSN: 2719-2725 (Online)

https://doi.org/10.36744/kf.624

(c) Creative Commons BY-NC-ND 4.0

Krzysztof Loska

Uniwersytet Jagielloński

https://orcid.org/0000-0003-4078-798X

\title{
Z punktu widzenia ludności rdzennej - film jako narzędzie dekolonizacji w Kanadzie
}

\author{
Słowa kluczowe: \\ media \\ autochtoniczne; \\ postkolonializm; \\ Pierwsze Narody \\ w Kanadzie; \\ film i technologia \\ audiowizualna
}

\begin{abstract}
Abstrakt
Tematem artykułu są sposoby wykorzystania technologii audiowizualnej przez artystów natywnych w Kanadzie. Realizowane przez nich filmy są rozważane w kontekście teorii postkolonialnej jako składnik szerszego procesu, w ramach którego ludność rdzenna przejmuje kontrolę nad wytwarzaniem obrazów i przedstawianiem (Kerstin Knopf). Przyjmując hipotezę, że dekolonizacja spojrzenia łączy się z walką o uznanie w wymiarze politycznym i odzyskanie kontroli nad własnym życiem, można stwierdzić, że twórcy rdzenni szybko dostrzegli korzyści płynące z zachodniej technologii i postanowili przejać narzędzia dawnych kolonizatorów po to, aby przepisać historię własnych narodów i opowiedzieć ją na nowo. Analizując filmy fabularne i dokumentalne nakręcone przez rėzyserów związanych m.in. z Isuma Productions, Wapikoni Mobile i Arnait Video Productions, można zauważyć, że ważną rolę odgrywa w nich poszukiwanie środków stylistycznych pozwalających wyrazić punkt widzenia mniejszości narodowych. Technologia nie jest postrzegana jako zagrożenie dla rodzimej kultury, lecz jako szansa na odbudowanie więzi wspólnotowych.
\end{abstract}


Pod koniec ubiegłego stulecia w kanadyjskich kręgach akademickich środki masowego przekazu postrzegano jako narzędzie oporu ludności rdzennej przed fragmentacją kulturową oraz dominacją anglofońskiej większości, pozwalające nie tylko na zachowanie języka czy dawnych obyczajów, lecz również na uzyskanie autonomii ${ }^{1}$. Zapewne dlatego część badaczy wskazywała na polityczny wymiar twórczości artystów natywnych oraz ich aktywność społeczną. Randolph Lewis posługiwał się określeniem „kino suwerenności”, chcąc podkreślić zaangażowanie reżyserów w walkę ze stereotypami rasowymi, niesprawiedliwością i nierównym traktowaniem oraz zwrócić uwagę na udział rdzennych twórców w batalii o uznanie i prawo do zachowania własnej kultury ${ }^{2}$. Z kolei Michelle Raheja, która łączyła płaszczyznę polityczną z kulturowa pisała o „wizualnej suwerenności” jako drodze do odzyskania wpływu na kreowanie wizerunku mniejszości narodowych i etnicznych w kinie ${ }^{3}$.

Wykorzystanie technologii filmowej, telewizyjnej i cyfrowej przez artystów natywnych można rozważać - jak czyni to Kerstin Knopf - w kontekście teorii postkolonialnej jako składnik szerszego procesu, w ramach którego ludność rdzenna przejmuje kontrole nad wytwarzaniem obrazów i przedstawianiem. W ten sposób powstaja zdekolonizowane dyskursy kulturowe, historyczne i polityczne uwolnione od zależności od dominującego, czyli hollywoodzkiego, modelu produkcji. Proces ten jest dwuetapowy: rozpoczyna się jako walka polityczna oparta na antykolonialnym przepisywaniu i filmowaniu historii, kreowaniu własnych obrazów, a następnie przekształca się w walke estetyczna, która polega na odrzuceniu obowiazujacych konwencji filmu etnograficznego lub negocjowaniu własnego stanowiska ${ }^{4}$.

Przez wiele lat obiektyw kamery skierowany na przedstawicieli narodów rdzennych (w Stanach Zjednoczonych, Kanadzie, Australii i Oceanii) stanowił odbicie punktu widzenia „białego człowieka” badającego obyczaje „ludzi pierwotnych", mieszkających z dala od "cywilizacji”. Nierzadko filmy zachodnich reżyserów powstawały ze szlachetnych pobudek, ponieważ ich twórcy pragnęli pokazać po raz pierwszy na ekranie prawdziwy obraz życia badanej społeczności ${ }^{5}$. Dotyczy to zarówno klasycznych dokumentów (W krainie łowców głów /In the Land of the Head Hunters, 1914/ Edwarda S. Curtisa czy Nanuk z Pótnocy /Nanook of the North, 1922/ Roberta J. Flaherty'ego), jak i najnowszych produkcji - choćby Niewidzialnego narodu (The Invisible Nation, reż. Richard Desjardins, Robert Monderie, 2007, 93 min), filmu opowiadającego o historii Algonkinów zamieszkujących okolice Montrealu w których wciąż obowiązuje milczące założenie, że narody rdzenne nie potrafią opowiedzieć o własnej przeszłości i potrzebują wsparcia z zewnątrz, żeby ich głos stał się słyszalny oraz zrozumiały dla zachodniej publiczności.

Jeśli przyjąć hipotezę, że dekolonizacja spojrzenia łączy się z walką o uznanie i odzyskanie kontroli nad własnym życiem, to należałoby stwierdzić, że artyści rdzenni szybko doszli do przekonania, iż powinni skorzystać z zachodniej technologii i przejąć narzędzia dawnych kolonizatorów po to, by przepisać historię i opowiedzieć ją na nowo. Z upływem czasu coraz ważniejszą rolę odgrywały wypowiedzi reżyserek - Marjorie Beaucage, Loretty Todd, Shelley Niro - które próbowały określić charakter estetyki natywnej i odpowiedzieć na pytanie: czym jest autentyczna twórczość ludów rdzennych? Chcąc uniknąć pułapki uwięzienia w kategoriach esencjalistycznych - na przykład propagowanej przez natywistów wizji powrotu do czasów poprzedzających kolonizację - twórcy wskazywali na 
uprzywilejowaną rolę form hybrydycznych, mieszanych ${ }^{6}$. Wielu z nich postrzegało technologię audiowizualną jako sposób na przywrócenie należnego miejsca przekazom ustnym, co potwierdzają filmy i wywiady Victora Masayesvy czy Zachariasa Kunuka. We wczesnym okresie działalności jednym z podstawowych celów artystów natywnych było obnażenie praktyk imperialnych oraz zdekonstruowanie stereotypów na temat własnego narodu, które dominowały w mediach głównego nurtu. Chodziło między innymi o krytyczny ogląd filmów fabularnych i etnograficznych, będących odzwierciedleniem spojrzenia władzy, uprzedmiotawiającego oraz uprawomocniającego imperialne panowanie.

Homi K. Bhabha, jeden z czołowych przedstawicieli teorii postkolonialnych, zauważył niegdyś, że stereotyp rasowy - stanowiący podstawę dyskursu kolonialnego i służący ideologicznej konstrukcji inności - jest zbudowany na dwuznaczności, zawiera pewien "nadmiar" wobec tego, co można udowodnić empirycznie lub wywieść logicznie ${ }^{7}$. Wytwarzane w ten sposób wyobrażenia służą wyartykułowaniu różnicy rasowej, dzięki czemu powstaje obraz zniewolonych ludzi jako osobników zwyrodniałych, których należy okiełznać i ucywilizować (stąd przymusowe odbieranie dzieci z rodzin natywnych i umieszczanie ich w szkołach $\mathrm{z}$ internatem). Kolonialny dyskurs w kinie i środkach masowego przekazu stał się jednym ze sposobów pozwalających skutecznie przekształcać wiedzę (film etnograficzny) we władzę (hegemonia kulturowa).

Stereotyp jest zatem pewnym uproszczeniem, choć nie dlatego, że zafałszowuje rzeczywistość, lecz z tego powodu, iż stał się utrwalona, zafiksowana forma przedstawienia8. To stereotyp tworzy kolonialną fantazję na temat "pierwotności" i „dzikości”, która wymaga nieustającego powtarzania, aby siła władzy mogła przetrwać. Zasadza się on na wymiarze wizualnym, ponieważ różnica koloru skóry jest natychmiast widoczna i wydaje się naturalna - to ona jest widzialnym znakiem niższości i podporządkowania, czyli źródłem dyskryminacji. Warto jednak pamiętać, że stereotypowi żądnego krwi i okrutnego barbarzyńcy, jaki wytworzyły amerykańskie westerny, zawsze przeciwstawiano wizerunek „,szlachetnego dzikusa”, podobnie jak obrazowi „prymitywnej kusicielki” towarzyszył fantazmat indiańskiej księżniczki Pocahontas.

Niektórzy badacze - jak James Weiner czy James Faris - uważaja że technologia filmowa, niezależnie od sposobu użycia, jest narzędziem dominacji kulturowej, bowiem stanowi przedłużenie zachodniego sposobu myślenia i patrzenia na świat; z kolei Faye Ginsburg i Terence Turner przekonująco uzasadniają że posługiwanie się zachodnią technologią nie prowadzi do asymilacji i przyswojenia innego systemu wartości oraz że możliwe jest wypracowanie alternatywnej strategii przedstawiania, dzięki której nastąpi odrodzenie tradycji, a zarazem szersze jej rozpropagowanie ${ }^{9}$. Dotyczy to zarówno języków ojczystych, jak i przechowania dla kolejnych pokoleń folkloru czy obrzędów religijnych, które ulegają zapomnieniu. Niemal wszyscy twórcy podkreślają znaczenie przekazu ustnego - jako kluczowego składnika pamięci zbiorowej - mogącego znaleźć swoje przedłużenie w technologii audiowizualnej za sprawą specyficznego podejścia do montażu i struktur narracyjnych, co widać zwłaszcza w filmach fabularnych, które opierają się na nielinearnej fabule, luźno powiązanych ze sobą epizodach, cyklicznej formule, pauzach i powtórzeniach. Amerykańska antropolog kulturowa Faye Ginsburg uznaje media narodów rdzennych za część szerszego ruchu na rzecz 
autonomii kulturowej i samostanowienia, bowiem są one wykorzystywane przez przedstawicieli mniejszości w celu odzyskania ich własnej przeszłości, historii - nierzadko traumatycznej - która została usunięta przez kulturę dominująca z oficjalnej narracji narodowej $i$ stopniowo popadła $w$ niepamięć ${ }^{10}$.

W 1968 r. członkowie narodów rdzennych Kanady po raz pierwszy otrzymali propozycję zrealizowania własnych projektów filmowych, co stało się możliwe dzięki powołaniu do życia nowej instytucji o nazwie Indian Film Crew finansowanej z programu Challenge for Change ${ }^{11}$. Najpierw zorganizowano warsztaty dla reprezentantów różnych plemion (Mohawków, Odżibwejów, Kri, Mikmaków i Haida), których przeszkolono w studiu w Montrealu, a następnie udostępniono im sprzęt. Pierwszym filmem, jaki wówczas powstał, była muzyczna krótkometrażówka Ballada o Stopie Wrony (The Ballad of Crowfoot, 1968, $10 \mathrm{~min}$ ), zrealizowana przez Williego Dunna (pochodzącego z plemienia Mikmaków) w formie montażu archiwalnych fotografii. Nieruchome kadry złożyły się na opowieść o tytułowym wodzu Czarnych Stóp, który w imieniu konfederacji plemion wynegocjował traktat pokojowy z ówczesnymi władzami prowincji ${ }^{12}$.

Wyróżnikiem działalności prowadzonej przez Indian Film Crew była praca zespołowa, co potwierdziły kolejne produkcje zrealizowane w ramach projektu: To jest mój lud (These Are My People, reż. Michael Mitchell, Willie Dunn, Barbara Wilson, Roy Daniels, 1969, 13 min) i Jesteś na ziemi Indian (You Are on Indian Land, reż. Michael Mitchell, 1969, 37 min) - obie nakręcone w rezerwacie Akwesasne. Pierwsza dotyczyła tradycji, spuścizny duchowej i religijnej, zaś druga - utrzymana w poetyce kina bezpośredniego - stanowiła interesujący przykład dokumentu zaangażowanego, krytycznie nastawionego do polityki rządu kanadyjskiego, zawierającego wyraźne przesłanie społeczne i polityczne ${ }^{13}$. Tematem przewodnim była w niej kwestia suwerenności, pokazana na przykładzie sporu (toczyli go Mohawkowie z lokalnymi urzędnikami o cła na towary), który przerodził się w blokadę mostu łączącego pograniczne stany Ontario i Nowy Jork.

Wchodząc w dekadę lat 70., członkowie zespołu przedstawili nowy projekt działalności na lata 1971-1973, w którym zwrócili uwagę na konieczność stworzenia stabilnej struktury umożliwiającej rozwój produkcji, co stałoby się możliwe dzięki powołaniu do życia Indian Film Unit - studia pozwalającego na szkolenie młodego pokolenia artystów rdzennych. Ich celem pozostało dokumentowanie życia codziennego współczesnych Indian, ale pragnęli też zachować na taśmie filmowej te elementy tradycji, wierzeń i praktyk plemiennych, które szybko zanikały i mogły zostać bezpowrotnie utracone ${ }^{14}$. Kierownictwo National Film Board ${ }^{15}$, finansujące twórczość artystów rdzennych, zaakceptowało program warsztatów, po których ukończeniu wybranym uczestnikom zaproponowano pracę na planie dokumentów realizowanych przez Boyce'a Richardsona i Tony'ego Ianzelo.

Na pierwszoplanową postać w kręgu artystów natywnych wyrosła wówczas Alanis Obomsawin (ur. 1932) - piosenkarka i aktywistka społeczna pochodząca z ludu Abenaków - która w 1971 r. zadebiutowała Świętami w Moose Factory (Christmas at Moose Factory, 13 min). Jej dokument poruszał kontrowersyjny temat szkół z internatem, w których od połowy XIX w. przymusowo umieszczano dzieci indiańskie. Na warstwę wizualną filmu składały się dziecięce rysunki komentowane przez kilkuletnich autorów. Bezduszny stosunek rządu kanadyjskiego do dzieci pochodzących z mniejszości etnicznych powracał w późniejszych filmach 
reżyserki, m.in. w przejmującym dokumencie o samobójstwie nastolatka, który całe życie spędził w sierocińcach i rodzinach zastępczych (Richard Cardinal: Cry from a Diary of a Métis Child, 1986, 29 min) ${ }^{16}$.

We wczesnych krótkometrażówkach (Czótno /The Canoe, 1972, 5 min/, Róg tosia /Moose Call, 1972, 5 min/, Xusum /1974, 4 min/, Koszyk /Basket, 1975, 7 min/) Obomsawin zajmowała się przede wszystkim rejestrowaniem lokalnych obyczajów. Podsumowaniem tego okresu jej aktywności twórczej jest Matka wielu dzieci (Mother of Many Children, 1977, 57 min) - hołd złożony kobietom należącym do Pierwszych Narodów, pokazujący ich walkę o zachowanie godności i odzyskanie należnej im pozycji w społeczeństwie, a przy tym przekonujący o znaczeniu tradycji przekazywanej z pokolenia na pokolenie. W wielu późniejszych produkcjach reżyserka pojawiała się osobiście, realizowała obrazy wpisujące się w konwencję dokumentu uczestniczącego, coraz częściej podejmowała przy tym tematy kontrowersyjne, związane z prawami człowieka oraz kluczową dla ludności rdzennej kwestią własności ziemi i zasobów naturalnych.

Nie zamierzam szerzej omawiać twórczości Alanis Obomsawin. Pragnę jedynie zwrócić uwagę na przykłady, które pokazuja, w jaki sposób film może zostać użyty jako narzędzie walki politycznej o prawa mniejszości. Przekonuje o tym zwłaszcza cykl filmów opisujących spór o kawałek ziemi należącej do Mohawków, na której lokalne władze postanowiły wybudować pole golfowe: Kanehsatake: 270 lat oporu (Kanehsatake: 270 Years of Resistance, 1993, 119 min), Mam na imię Kahentiiosta (My Name Is Kahentiiosta, 1995, 29 min), Spudwrench - Kahnawake Man (1997, $58 \mathrm{~min}$ ). Wszystkie te dokumenty odnoszą się do burzliwych protestów, do których doszło latem 1990 r. w małej miejscowości Oka położonej nad rzeką Ottawa (w prowincji Quebec) ${ }^{17}$. Pomimo zaangażowania licznych sił porządkowych władzom nie udało się stłumić oporu oraz powstrzymać aktywistów przed zablokowaniem dróg i mostów.

W pierwszym z filmów, Kanehsatake: 270 lat oporu - wyróżnionym na międzynarodowych festiwalach w Toronto, Vancouver i Amiens - Obomsawin rozmawiała nie tylko z Mohawkami, lecz również z dowódcami wojskowymi i żołnierzami, zarejestrowała starcia z policja, konsekwentnie łączyła techniki obserwacyjne $z$ dokumentem uczestniczącym ${ }^{18}$. Odmienną strategią posłużyła się w drugim z filmów, który opowiada o kobiecie aresztowanej podczas zamieszek pod zarzutem... odmowy podania kanadyjskiego nazwiska. Natomiast w trzeciej produkcji reżyserka przedstawiła swoją rozmowę z robotnikiem budowlanym biorącym udział $w$ protestach. W przeciwieństwie do dokumentów realizowanych przez następne pokolenie twórców natywnych, jej filmy mają klasyczną konstrukcję. Obomsawin przedstawia chronologiczny przebieg wydarzeń, wykorzystuje formę wywiadu oraz posługuje się komentarzem autorskim spoza kadru. Zawsze kręci w autentycznej scenerii, unika inscenizowanych rekonstrukcji, zmierza do podważenia oficjalnej wersji historii narzuconej przez dominującą kulturę. Interesuje ją doświadczenie zwykłych ludzi pochodzących z mniejszości etnicznych, dlatego oddaje głos swoim bohaterom.

Młodsze pokolenie artystek natywnych wybiera nieco inną poetykę, zamazuje granice gatunkowe, o czym świadczy twórczość Shelley Niro (ur. 1954). Począwszy od krótkometrażowego debiutu Zaczyna się od szeptu (It Starts with a Whisper, 1993, 28 min), autorka z plemienia Mohawków zrywa z realizmem, nie 
korzysta z formuły ani klasycznego dokumentu obserwacyjnego, ani uczestniczącego, nie odnosi się do wydarzeń historycznych, natomiast wyróżnia się skłonnością do eksperymentów stylistycznych, zamiłowaniem do satyry, pastiszu i parodii. Przekonuje o tym jej średniometrażowa fabuła Honey Moccasin (1998, 48 min), w której konwencje filmu detektywistycznego mieszają się z komedia, zaś nielinearna i epizodyczna akcja, pełna dygresji i komentarzy metanarracyjnych, służy podważeniu stereotypowych wyobrażeń na temat kultury plemion rdzennych (w tym wypadku Mohawków). Głównymi bohaterami są: Honey (Tantoo Cardinal) - właścicielka baru „Smokin Moccasin”, jej córka Mabel (Florence Belmore) - artystka, performerka i reżyserka oraz Zachary John (Billy Merasty) - przybysz z zewnątrz, gej i transseksualista, właściciel konkurencyjnego lokalu o nazwie „Inukshuk Café”, w którym nie podaje się alkoholu i obowiązuje zakaz palenia, ale w zamian organizuje się imprezy karaoke ${ }^{19}$.

W filmie Shelley Niro dominuje karnawałowa „logika odwrotności” - by posłużyć się określeniem Michaiła Bachtina - nie tylko ze względu na ciągłe podważanie obowiązujących hierarchii i wyśmiewanie wszystkiego, ale także z uwagi na zamierzoną wielogłosowość oraz obecność wstawek autotematycznych, które rozbijają ciągłość narracji i potęgują efekt obcości. Najlepszym przykładem tej strategii jest sekwencja performance'u Mabel, połączonego z prezentacją jej eksperymentalnej krótkometrażówki. Po zakończeniu występu Zachary zwraca się do bohaterki, a pośrednio także do widzów: Myślę, że całość wypadła zupetnie dobrze. Być może była trochę przerażajaca i nazbyt trudna, bo przecież wieczór powinno się przeznaczyć na rozrywkę. Chcemy zapomnieć o problemach i nie stuchać o mrocznych sprawach. Może się wydawać, że film Niro nie należy do nurtu kina zaangażowanego (z taką klasyfikacją mieliśmy do czynienia w przypadku Alanis Obomsawin), a jednak artystka konsekwentnie czyni aluzje do kwestii problematycznych w historii narodów rdzennych. W tle opowieści pojawia się temat dzieci odbieranych rodzinom indiańskim: jedna $\mathrm{z}$ fotografii przedstawia zakonnice niosące niemowlęta, na innym zdjęciu widać dzieci przebrane w stroje plemienne, odgrywające role Indian, a tytułowa bohaterka na chwilę zmienia się w Pocahontas - symbol zależności kolonialnej.

Nieco bardziej konwencjonalny $w$ formie jest długometrażowy debiut fabularny Niro, Pocałunek Lightninga (Kissed by Lightning, 2009, 89 min), wpisujący się w nurt kina posttraumatycznego. Główna bohaterka Mavis Dogblood (Kateri Walker) nie może się pogodzić ze stratą ukochanego męża Jessiego Lightninga (Michael Greyeyes). Pragnąc zachować pamięć o nim, maluje obrazy, w których opowiada historię ich związku, co sprawia, że dochodzi do powiązania różnych płaszczyzn czasowych, przeszłości i teraźniejszości. W filmie przenikają się również dwa światy - realny i fantazmatyczny - nie tylko za sprawą sceny marzeń sennych, obecności duchów przodków i zmarłego męża, ale również dlatego, że reżyserka sięga do klasycznej legendy irokeskiej o wodzu Hiawacie, który dzięki pomocy swojego mistrza i nauczyciela Daganawidy - Wielkiego Rozjemcy - zjednoczył plemiona Mohawków, Oneidów, Onondagów, Kajugów i Seneków oraz założył Ligę Pięciu Narodów ${ }^{20}$. Mavis maluje serię obrazów ilustrujących podania ludowe, chcąc w ten sposób kontynuować temat podjęty przez męża w jego kompozycjach pisanych tuż przed śmiercią. Podobnie jak w innych omawianych filmach, także w tym pojawia się opowieść o tożsamości etnicznej, poszukiwaniu 
korzeni, odzyskiwaniu tradycji, choć całość została tu opowiedziana za pomocą klasycznych schematów gatunkowych z wykorzystaniem dość oczywistej symboliki: flaga Pierwszych Narodów, czółno, amulet indiański, obrazy przyrody.

Mieszanie różnych poetyk i gatunków - przy równoczesnym zaangażowaniu społecznym - nie jest czymś wyjątkowym dla artystek natywnych, o czym świadczą filmy Christine Welsh i Lisy Jackson. Pierwsza z nich jest autorką dokumentu Szukajac Dawn (Finding Dawn, 2006, 73 min) o zaginionych i zamordowanych kobietach z narodów rdzennych, druga nakręciła krótkometrażówkę Dzikuska (Savage, 2009, 6 min), utrzymaną w konwencji musicalu, o dzieciach przymusowo umieszczanych w szkołach z internatem. Jackson konsekwentnie wplata do swych dokumentów elementy kultury popularnej, posługuje się wstawkami animowanymi (Suckerfish, 2004, $8 \mathrm{~min}$ ), twórczo wykorzystuje muzykę i taniec (Pow.Wow.Wow, 2011, 3 min) oraz formę performance'u, jak w Sidłach (Snare, 2013, 4 min), w których opowiada o brutalności i przemocy wobec kobiet natywnych. Jak zauważyła Karine Bertrand, do form hybrydycznych jako narzędzia oporu chętnie sięgają artystki multimedialne (m.in. Caroline Monnet, Alethea Arnaquq-Baril, Zoe Leigh Hopkins, Elle-Maija Tailfeathers), które do swoich projektów artystycznych włączają materiały archiwalne, wstawki fabularne i animowane, domowe wideo, nierzadko po to, by powiązać narrację autobiograficzną z wypowiedzią polityczna, protestem przeciw przemocy i nierówności ekonomicznej lub rasowejej

Na przełomie stuleci ważną rolę odgrywały warsztaty filmowe przeznaczone dla kobiet z narodów rdzennych, prowadzone w ramach kolektywu Arnait Video Productions, założonego w 1991 r. przez grupę artystek związanych z wytwórnią Igloolik Isuma: Susan Avingaq, Marie-Hélène Cousineau, Matildę Haniliaq, Julie Ivalu, Madeline Ivalu, Mary Kunuk, Marthę Maktar i Celinę Uttuigak. Dekolonizacja mediów oznaczała dla nich konieczność oddania głosu kobietom natywnym przez stworzenie platformy, na której mogłyby opowiedzieć własne historie, przekazać osobiste doświadczenie. Koordynatorką tych działań została Marie-Hélène Cousineau (ur. 1960), pochodząca z Quebecu, współpracownica Zachariasa Kunuka i założycielka ośrodka kultury wideo Tariagsuk. Z początku chodziło o nabranie doświadczenia i opanowanie techniki, dlatego filmy nie miały szerszej dystrybucji, wyświetlano je wyłącznie na zamkniętych pokazach. Jednym z pierwszym projektów, który pokazano publicznie, był dokument Lampa (Qulliq, reż. Marie-Hélène Cousineau, 1993, 10 min) z udziałem Susan Avingaq i Madeline Ivalu. Obie kobiety opowiadają w nim, jak wytwarzało się kamienną lampę. Narzędzie to służyło nie tylko do oświetlania i ogrzewania pomieszczenia mieszkalnego, ale także jako palenisko do podgrzewania wody ${ }^{22}$. Podobnie jak w filmach Kunuka (piszę o nich w dalszej części artykułu), mamy tu do czynienia z przykładem praktyk rekonstrukcyjnych oraz wykorzystaniem filmu jako medium pamięci, nie tyle w znaczeniu nostalgicznego przedstawiania przeszłości, będącego wyrazem tęsknoty za tym, co utracone, ile raczej sposobu przechowywania wiedzy o zwyczajach Inuitów.

Nie znaczy to bynajmniej, że walory etnograficzne są fundamentalne dla produkcji realizowanych przez Arnait Video Productions, ponieważ równie ważną rolę odgrywają osobiste wspomnienia przekazywane z pokolenia na pokolenie, jak chociażby w filmie Matka (Anaana, reż. Mary Kunuk, Marie-Hélène Cousineau, 2001, 53 min). Vivi Kunuk opowiada w nim o swoim dzieciństwie, przybranych 
rodzicach, mężu, z którym wychowała ośmioro dzieci (w tym Zachariasa Kunuka), oraz życiu na Ziemi Baffina. Jej wypowiedziom towarzyszą obrazy z życia codziennego (np. zabawy dzieci w rzece, sceny z polowania na foki), zaś na ścieżce dźwiękowej słychać pieśni ludowe i wiersze. Filmy kręcone przez kobiety związane z kolektywem Arnait nierzadko miały funkcję terapeutyczna, służyły do uporania się z bolesną przeszłością przymusową asymilacją upokorzeniami ze strony białej większości, a jednocześnie były próbą zaleczenia ran i odbudowania życia.

W 2008 r. powstał pierwszy film fabularny wyreżyserowany przez Marie-Hélène Cousineau i Madeline Ivalu. Scenariusz W przeddzień (Before Tomorrow /Le jour avant le lendemain/, $93 \mathrm{~min}$ ) powstał na podstawie powieści pod tym samym tytułem (Før morgendagen) napisanej przez duńskiego pisarza Jørna Riela. Akcja rozgrywa się w połowie XIX w. na północnych krańcach Quebecu i choć opowiada o losach dwóch rodzin, to skupia się na starszej kobiecie i jej wnuku. Film wyświetlono na przedpremierowym pokazie dla mieszkańców miasteczka Igloolik, gdzie mieści się siedziba Arnait; rok później otrzymał nominacje do kanadyjskiej nagrody Genie w dziewięciu kategoriach (m.in. za najlepszy film, reżyserię, główną rolę męską i żeńską). W roku 2013 obie reżyserki nakręciły kolejną fabułę, zatytułowaną Ja (Uvanga, 89 min), opowiadającą o młodej kobiecie z Montrealu, która po śmierci ukochanego wyrusza wraz z synem na daleką północ, by poznać inuicką rodzinę męża.

W 2004 r. dzięki wsparciu z National Film Board powstało stowarzyszenie Wapikoni Mobile (wapikoni znaczy „kwiat”), założone przez Manon Barbeau z zamiarem dotarcia do wspólnot natywnych z warsztatami, dzięki którym młodzi ludzie mogliby zdobyć umiejętności potrzebne do realizacji filmów. W ciągu kilkunastu lat w przedsięwzięciu tym wzięło udział pięć tysięcy przedstawicieli różnych grup etnicznych, którzy nakręcili ponad tysiąc krótkometrażówek. Niektóre z przygotowanych projektów wyświetlano na międzynarodowych festiwalach (w Brukseli, Toronto i Montrealu), jak chociażby trylogię Kevina Papatie: Przyszłość (Wabak, 2006, 6 min), Poprawka (L'amendement, 2007, 4 min), Drzewo i kora (L'arbre et l'écorce, 2008, $4 \mathrm{~min}$ ). Podczas pierwszych odwiedzin w rezerwatach indiańskich i osadach inuickich organizatorzy warsztatów musieli przełamać nieufność mieszkańców, jednak dzięki poparciu ze strony członków parlamentu Pierwszych Narodów Quebecu i Labradoru udało im się przekonać ludzi do współpracy ${ }^{23}$.

Główną funkcją warsztatów - oprócz przeszkolenia technicznego oraz udostępnienia podstawowych narzędzi (kamera, stół montażowy) - było zintegrowanie wspólnoty narodów rdzennych, połączenie tradycji z nowoczesną technologia, uwrażliwienie uczestników kursów na kwestie ekologiczne, obyczajowe i polityczne oraz odbudowanie wzajemnego zaufania i więzi międzypokoleniowych. W wielu filmach powraca kwestia zmian zachodzących w kulturze, spowodowanych rozwojem komunikacji elektronicznej, o czym opowiadają Alland Flamand i Patrick Boivin w Terytorium fal (Territoire des ondes, 2006, 11 min), wskazując na przeniesienie dawnych sposobów porozumiewania się za pomocą pieśni i tańców do nowego medium. Tematyka ekologiczna pojawia się u Shelley Niro, która w 2006 r. nakręciła pięciominutowy film Drzewo (Tree) o dniu z życia Matki Ziemi, pełen odniesień do irokeskiej kosmologii, z wyraźnym przesłaniem politycznym ${ }^{24}$. Realizacja ta wpisuje się w nurt posthumanistyczny w sztuce współczesnej, po- 
nieważ główna bohaterka (w tej roli wystąpiła Lena Recolett - poetka, artystka wizualna i piosenkarka) konsekwentnie podważa binarne opozycje między naturą i kulturą oraz tym, co ludzkie, i tym, co nie-ludzkie. Ochrona środowiska naturalnego łączy się nierzadko z tematem obrony terytoriów plemiennych, o czym przekonują liczne dokumenty: Nasza ziemia (Kitaskino /Notre territoire/, reż. Henman W. Niquay, 2007, 4 min), Zagrożenie (Kushtakuan, reż. Langis Fortin, Nemnemiss McKenzie, 2009, 4 min), Recykler (Le recycleur, reż. Érik Papatie, 2009, 9 min). Natura jest w nich przedstawiana jako źródło tożsamości zbiorowej i fundament wspólnoty wyobrażonej: Jesteśmy woda, jesteśmy ziemia, jesteśmy zwierzętami, jesteśmy rodzina, jesteśmy lasem - ogłasza Kevin Papatie w zrealizowanym przez siebie Jesteśmy (Nous sommes, 2009, 4 min), swoistym manifeście skierowanym do ludów rdzennych.

Pod koniec ubiegłego stulecia Igloolik - mała osada położona w północnozachodniej części Kanady, zamieszkana przez półtora tysiąca ludzi - stała się inuickim centrum kultury. Jednak nie tylko z powodu założonej tam wytwórni filmowej Isuma Productions oraz lokalnego oddziału Inuit Broadcasting Corporation, ale również za sprawą licznych artystów plastyków, muzyków i poetów, którzy pracowali na tej niewielkiej wyspie. Isuma (w języku inuickim „myśl”, "mądrość") powstała w 1990 r. na drugim piętrze dużego budynku, w którym na parterze działało Tariagsuk Video Centre oraz studio montażowe. Współzałożycielami tego niewielkiego kolektywu artystycznego byli Zacharias Kunuk, Paul Apak Angilirq, Norman Cohn i Pauloosie Qulitalik ${ }^{25}$, którzy kilka lat wcześniej wspólnie nakręcili dla Inuit Broadcasting Corporation półgodzinny dokument Z punktu widzenia Inuka (From Inuk Point of View, 1985). Rozczarowani biurokracją i brakiem perspektyw rozwoju w relatywnie dużej stacji telewizyjnej, postanowili rozpocząć karierę niezależna, w przekonaniu, że uda im się poprowadzić firmę dzięki grantom państwowym. W kolejnych latach powstawały filmy kręcone zgodnie z modelem przyjętym w społeczności inuickiej, opierającym się na współpracy, swobodzie twórczej, zbiorowym podejmowaniu decyzji artystycznych oraz uczestnictwie wszystkich na każdym etapie produkcji.

Zacharias Kunuk nie postrzegał nowych technologii jako zagrożenia dla tradycyjnej kultury, ale jako szansę, narzędzie wspomagające, pozwalające na upowszechnianie wiedzy o lokalnych obyczajach łowieckich, kulturze materialnej i duchowej Inuitów. Przykładem takich założeń artystycznych oraz ideologicznych jest trzynastoodcinkowa seria półgodzinnych filmów dokumentalnych pod wspólnym tytułem Nunavut (1995), czyli „Nasz kraj”, będących próbą rekonstrukcji życia wspólnoty inuickiej z połowy lat 40. ubiegłego wieku. Pierwszy odcinek, Psi zaprzeg (Qimuksiq), rozpoczyna się tuż przed zakończeniem II wojny światowej, podczas gdy akcja ostatniego, Szczęśliwe dni (Quviasuvik), rozgrywa w grudniu 1946 r., dzięki czemu twórcom udało się nie tylko pokazać odmienność kulturową tradycje i obyczaje mieszkańców północnych regionów Kanady, ale również zasygnalizować świadomość wydarzeń historycznych, których echa docierały do inuickiej społeczności. Pierwszoplanową rolę odgrywało pokazanie życia codziennego mieszkańców oraz postępujących zmian spowodowanych kolonizacją. W drugim odcinku (Avaja) bohaterowie przyglądają się, jak na wzgórzu jest budowany kościół, a śpiewy przerywa bicie dzwonu; w odcinku dziewiątym (Mors /Aiviaq/) do osady przybywa misjonarz, który pragnie badać życie Inuitów; wreszcie w ostatnim odcinku dochodzi do połączenia dawnych obyczajów z nowymi (święta Bożego Narodzenia). 


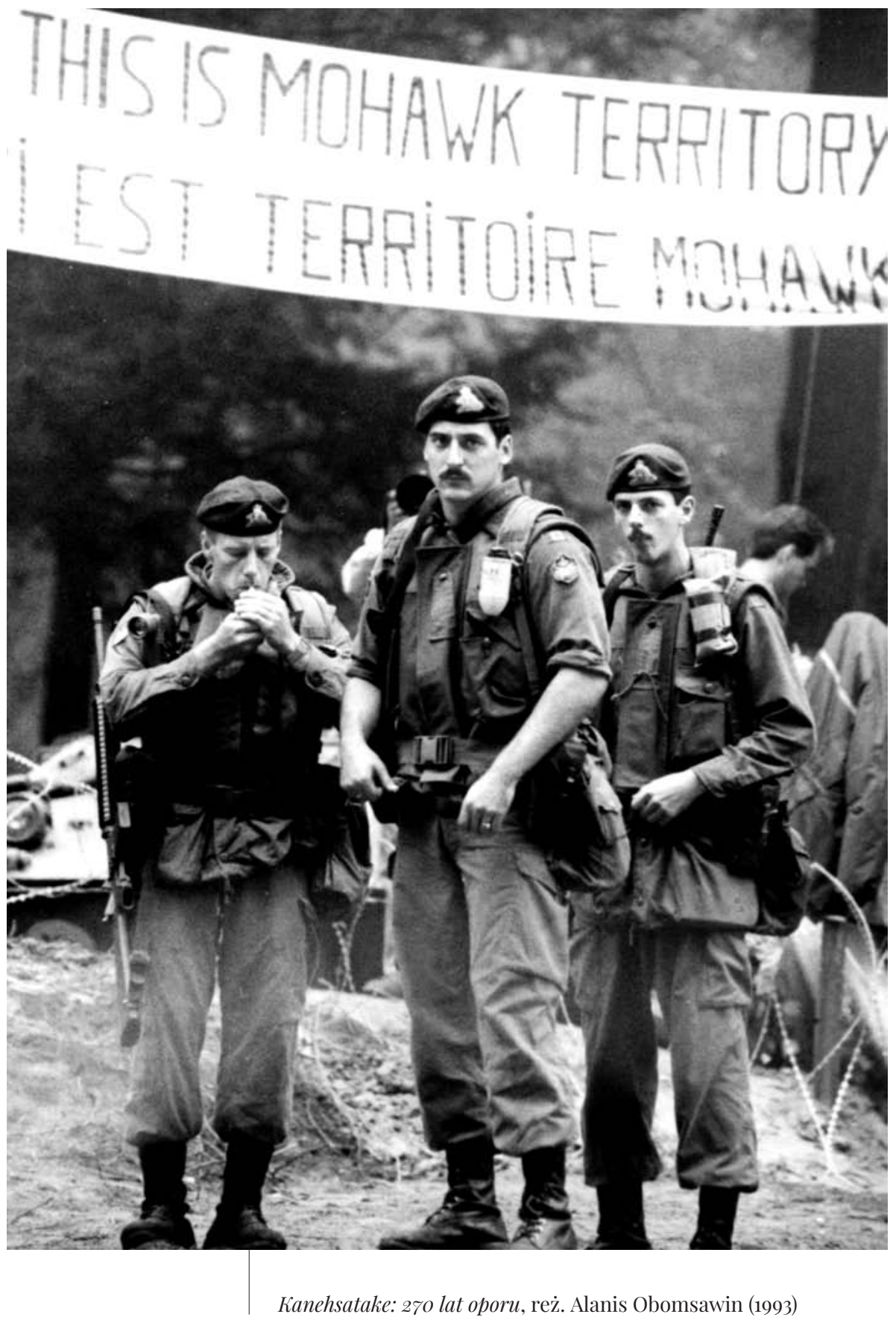



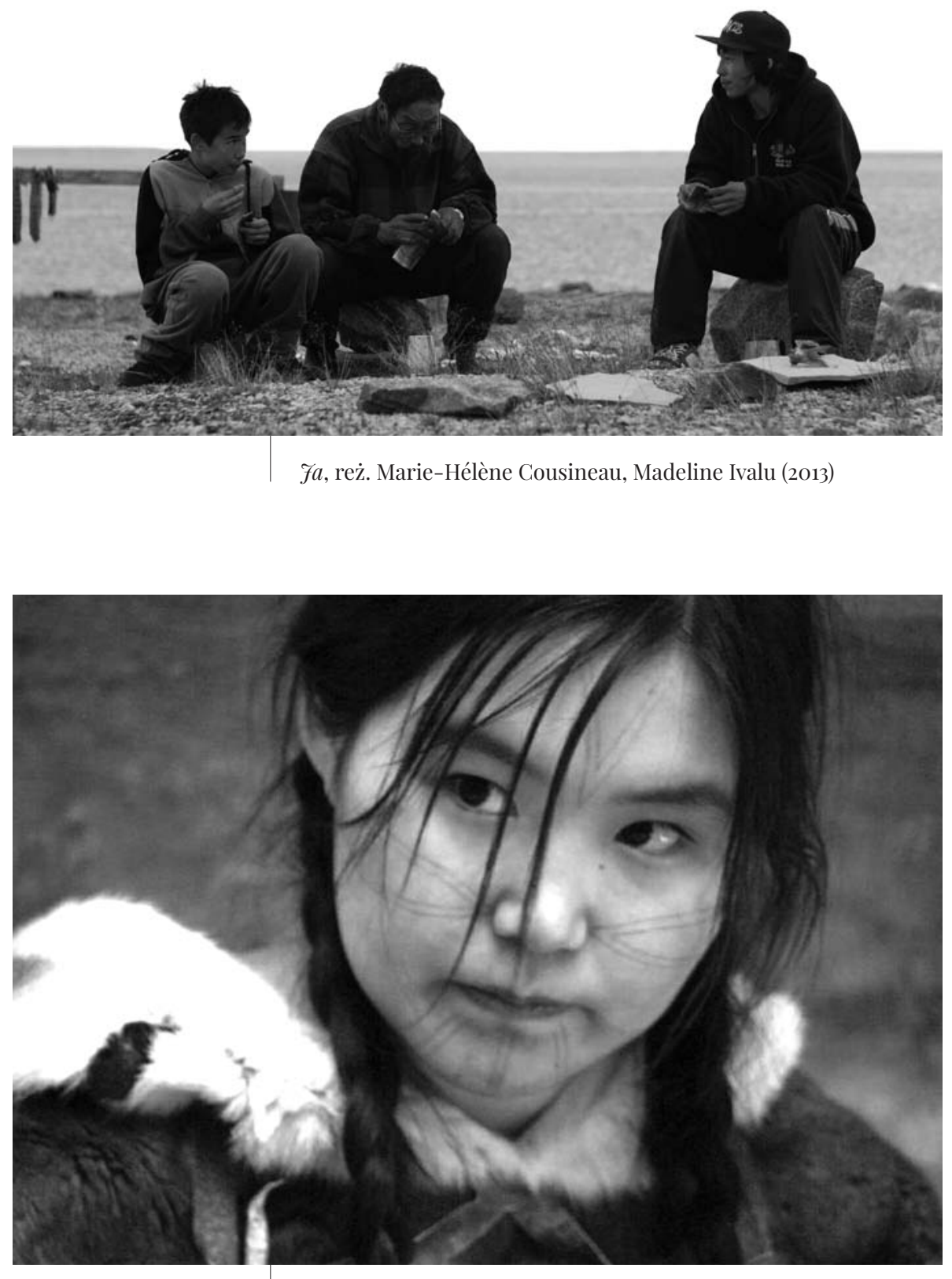

Dzienniki Knuda Rasmussena, reż. Zacharias Kunuk (2006) 
Można się zgodzić z amerykańską badaczką Shari M. Huhndorf, która twierdzi, że w krótkometrażowych filmach dokumentalnych wykorzystujących praktyki rekonstrukcyjne Kunukowi udało się opowiedzieć nie tylko o przemianach w życiu codziennym Inuitów spowodowanych ingerencją kolonizatorów, ale również o powstaniu nowej wspólnoty wyobrażonej. Dokonało się to dzięki środkom masowego przekazu, które stały się ważnym narzędziem budowania więzi społecznych pomiędzy mieszkańcami dalekiej północy żyjącymi w dużym rozproszeniu $^{26}$. W kolejnych odcinkach przedstawiciele starszyzny plemiennej wskazują na konieczność przystosowania się do rzeczywistości, która nastała, potrzebę połączenia dawnych wierzeń i obyczajów z nowymi przy zachowaniu suwerenności i kontroli nad własnym życiem i historią.

Niewątpliwie najważniejszym filmem, jaki wyprodukowano w Igloolik Isuma, był Atanarjuat, biegacz (Atanarjuat: The Fast Runner, reż. Zacharias Kunuk, 2001, 172 min) - dzieło wyróżnione licznymi nagrodami na festiwalach w Cannes, Edynburgu, Montrealu, San Diego i Gandawie. Scenariusz powstał na podstawie starej legendy, po raz pierwszy spisanej przez George'a Lyona, który dowodził brytyjską ekspedycją polarną w latach 1821-1823, oraz jej wersji utrwalonej przez duńskiego badacza i podróżnika Knuda Rasmussena sto lat później²7. Film opowiada o złamaniu zakazu, zazdrości, rywalizacji, zbrodni, zemście i pojednaniu. Główny temat został zapowiedziany w prologu rozgrywającym się dwadzieścia lat wcześniej, kiedy to do osady inuickiej przybył obcy szaman, co doprowadziło do konfliktu wśród członków małej społeczności. Nigdy się nie dowiedzieliśmy, kim był ani dlaczego wszystko to się wydarzyło. Zło przybyło do nas jak śmierć. I musimy z tym $\dot{z} y c ́$ - mówi żona zabitego przywódcy małej wspólnoty inuickiej. Przyczyną nieszczęścia jest pragnienie władzy oraz wygórowana ambicja, która prowadzi do zniszczenia więzi międzyludzkich.

Przygotowując się do realizacji długometrażowego debiutu fabularnego, którego akcja rozgrywała się w czasach poprzedzających kolonizację, Zacharias Kunuk przystąpił do drobiazgowej rekonstrukcji kultury materialnej swojego narodu, zgromadził bogatą dokumentację, dzięki czemu wszystkie narzędzia używane przez bohaterów sprawiały wrażenie autentycznych: sanki - główny środek transportu - wykonano z poroża karibu, do połowu ryb używano widlastej włóczni (kakivah), kobiety posługiwały się zakrzywionym nożem (ulu), a mężczyźni - dzidą (unaaq) oraz harpunem (sakku), ich oczy przed promieniami słonecznymi chroniły okulary (iggak) zrobione z kości karibu, zaś namioty uszyto z foczych skór. Rekonstrukcja była dla Kanuka narzędziem krytycznym pozwalającym zrozumieć relację między przeszłością a teraźniejszością. Nie wszyscy badacze widzieli w tym filmie przykład strategii oporu antykolonialnego; niektórzy pisali o fetyszyzowaniu „,autentycznej kultury” ludów rdzennych, eskapistycznej fantazji, pułapce rekonstruowania przeszłości oraz unikaniu konfrontacji ze współczesnymi problemami, z jakimi mierzą się Inuici ${ }^{28}$.

Pisząc o rekonstrukcji (re-enactment), nie mam na myśli jedynie wąskiego znaczenia tego pojęcia, w którym chodzi o odtwarzanie historii czy upamiętnianie minionych wydarzeń, ale za Rebeccą Schneider pragnę zwrócić uwagę na coś więcej: aktualizację przeszłości w życiu teraźniejszym, performatywne powtórzenie będące rodzajem pamięci ucieleśnionej ${ }^{29}$. O tym aspekcie rekonstrukcyjnym myślał Zacharias Kunuk, kiedy w napisach końcowych wprowadzał wstawki z planu fil- 
mowego, które podważały wrażenie realności i obnażały fikcyjną naturę performatywnej inscenizacji ${ }^{30}$.

Atanarjuat doskonale ilustruje strategię zdobywania suwerenności przez artystów natywnych, o której Scott Lyons pisał, że polega nie tyle na odzyskiwaniu przeszłości, ile raczej na pezwnej możliwości31. Nie chodzi o mamienie widzów przywróceniem „nieskażonej tradycji”, ale o praktykę autoetnograficzną będącą odpowiedzią na dominujący dyskurs wytworzony przez dawnych kolonizatorów. Film Kunuka nie jest dziełem eskapistycznym, nie służy ucieczce od współczesnych problemów, ale sugeruje możliwość odnalezienia korzeni i włączenia ich do teraźniejszego życia Inuitów. Rekonstrukcja przeszłości nie jest nostalgicznym przywoływaniem tego, co utracone, a co być może nigdy nie istniało, lecz performatywnym odgrywaniem praktyk życia codziennego przypominającym kształtowanie tradycji. Jak zauważył Michael Robert Evans, reżyserowi chodziło o podważenie stereotypowych wyobrażeń na temat Inuitów, których z jednej strony przedstawiano jako ofiary nowoczesności, zmuszone do przyjęcia zachodnich wzorów i pozbawione dziedzictwa przodków, zaś z drugiej widziano w nich przeciwników cywilizacji zapatrzonych w przeszłość, przywiązanych do dawnego stylu życia ${ }^{32}$. Kunuk proponuje trzecie spojrzenie, zgodnie z którym Inuici z upodobaniem korzystają z narzędzi i udogodnień oferowanych im przez współczesny świat, lecz nie rezygnują ze elementów tradycji nadal odpowiadających na ich potrzeby.

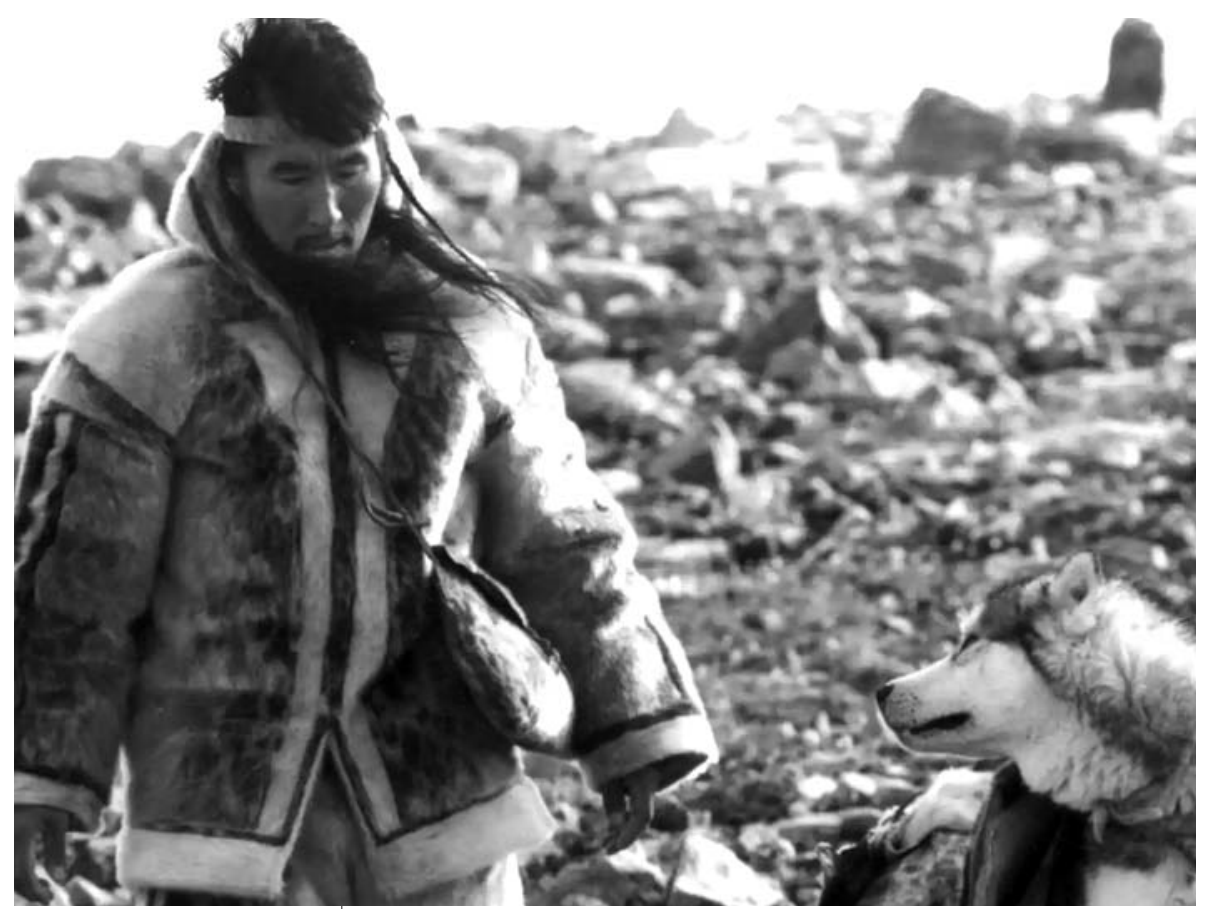

Atanarjuat, biegacz, reż. Zacharias Kunuk (2001) 
Rozwinięciem pomysłów przedstawionych w debiucie fabularnym są jego Dzienniki Knuda Rasmussena (The Journals of Knud Rasmussen, 2006, 112 min), które w sposób bezpośredni odnoszą się do zgubnych skutków kolonizacji, pokazują wpływ misjonarzy i kompanii handlowych na zmianę stylu życia. Zacharias Kunuk mówi o wydarzeniach opisanych przez duńskiego podróżnika, który w latach 1921-1924 przebywał wśród Inuitów, słuchał ich opowieści i zbierał ustne podania, a wyniki badań opublikował $\mathrm{w}$ dziesięciotomowej monografii. Wbrew tytułowi bohaterem filmu nie jest Knud Rasmussen, lecz inuicki szaman Avva, któremu towarzyszą żona Orulu i córka Apak. Reżyser konsekwentnie odwraca spojrzenie kolonialne, oddaje głos Inuitom, pokazuje zgubne skutki kontaktu z cywilizacja, ale wskazuje przy tym możliwość odrodzenia kulturowego. Kluczowa, kilkunastominutowa sekwencja rozmowy Avvy z Rasmussenem została nakręcona w poetyce dokumentalnej. Stary szaman opowiada duńskiemu podróżnikowi o wierzeniach, zwyczajach plemiennych, roli tańców i pieśni: Postępujemy zgodnie z zasadami przekazanymi przez przodków, ponieważ one nadal działaja.

W Dziennikach Knuda Rasmussena Kunuk skupia się na rekonstrukcyjnych praktykach performatywnych, począwszy od zwykłych czynności życiowych po pieśni i opowieści, a dzięki częstym odniesieniom do dokumentów źródłowych, filmów etnograficznych i historycznych fotografii problematyzuje kwestię archiwum, które jest nie tylko miejscem gromadzenia wiedzy, ale też sposobem jej wytwarzania ${ }^{33}$. Pisząc o społecznościach wykluczonych, naznaczonych kolonizacją Diana Taylor wprowadziła rozróżnienie między archiwum i repertuarem, stwierdzając, że to drugie pojęcie wiąże się z praktykami cielesnymi, czy może raczej z pamięcią ucieleśniona, na którą składają się gesty, opowieści, sposoby poruszania się, taniec i śpiew, czyli wszystko to, co ulotne, uchwycone "tu i teraz", co domaga się aktywnego udziału żywych ludzi ${ }^{34}$. Chodzi tu zatem o narracje mówione, uroczystości i formy obrzędowe bądź twórczość artystyczna, a zatem praktyki wymagające uczestnictwa, wspólnej przestrzeni wytwarzania i odbioru.

W filmowych rekonstrukcjach udało się Kunukowi uchwycić to, co stanowi repertuar kulturowy Inuitów, co świadczy zarówno o ciągłości, jak i rozwoju. Nie znaczy to bynajmniej, że przedmiot archiwalny jest dla niego nieistotny. Wręcz przeciwnie - może on odgrywać rolę katalizatora ucieleśnionej aktywności w obrębie praktyk performatywnych. Jednak w Dziennikach... reżyser sugeruje, że zapis nie jest podstawowym źródłem wiedzy oraz że zawiera powierzchowny lub jednostronny obraz rzeczywistości, co potwierdzają obszerne monologi Avvy, Apak i Orulu, którzy opowiadają o życiu codziennym, obyczajach i rytuałach Inuitów. W proponowanym przez Kunuka podejściu można dostrzec przykład spojrzenia autoetnograficznego, ponieważ rekonstrukcje są powtórzeniem praktyk z przeszłości w nowym kontekście, wytwarzają coś, co Sylvie Jasen nazwa performance'em wiedzy. Nie chodzi w nich wyłącznie o mechaniczne odtworzenie, ale reaktualizację, spontaniczną improwizację, która jest przeciwieństwem zinstytucjonalizowanych form pamięci ${ }^{35}$.

Technologie audiowizualne, którymi posługiwali się artyści natywni związani z Indian Film Crew, Isuma Productions, Wapikoni Mobile i Arnait Video Productions, okazały się doskonałym narzędziem przechowywania i przekazywania tradycyjnej wiedzy oraz sposobem na odzyskanie głosu i opowiedzenie własnej 
historii, a nawet na swoisty powrót uprzywilejowanej formy przekazu ustnego w epoce elektronicznej ${ }^{36}$. Można zauważyć, że w omawianych filmach fabularnych i dokumentalnych ważną rolę odgrywa poszukiwanie środków stylistycznych pozwalających wyrazić punkt widzenia narodów rdzennych. Zapis na taśmie filmowej i kasecie wideo nie tylko ułatwił przywrócenie pamięci czy zdekonstruowanie stereotypowych wyobrażeń rasowych, lecz również został wykorzystany do poradzenia sobie $\mathrm{z}$ traumatycznym dziedzictwem kolonializmu oraz do walki o uznanie w wymiarze politycznym.

${ }^{1}$ Por. F. Ginsburg, Indigenous Media: Faustian Contract or Global Village?, „Cultural Anthropology" 1991, t. 6, nr 1, s. 92-112; M. R. Evans, Hegemony and Discourse: Negotiating Cultural Relationships Through Media Production, "Journalism: Theory, Practice \& Criticism" 2002, t. 3, nr 3, s. 309-329.

${ }^{2}$ Por. R. Lewis, Cinema of Sovereignty, w: tegoż, Alanis Obomsawin: The Vision of a Native Filmmaker, University of Nebraska Press, Lincoln 2006, s. 156-194.

${ }^{3}$ M. H. Raheja, Reading Nanook's Smile: Visual Sovereignty, Indigenous Revisions of Ethnography, and "Atanarjuat: The Fast Runner", w: Native Americans on Film Conversations, Teaching, and Theory, red. M. E. Marubbio, E. L. Buffalohead, The University Press of Kentucky, Lexington 2013, s. 58-88.

${ }^{4} \mathrm{~K}$. Knopf, Decolonizing the Lens of Power: Indigenous Films in North America, Editions Rodopi, Amsterdam - New York 2008, s. 63.

${ }^{5}$ Indianie zostali pokazani na ekranie po raz pierwszy w 1894 r. przez Williama Kennedy'ego Dicksona, który przy użyciu kamery Edisona nakręcił kilkudziesięciosekundowy film Taniec ducha Siuksów (Sioux Ghost Dance) $\mathrm{z}$ udziałem Indian z rewii Buffalo Billa. W roku 1901 (lub 1903) w wytwórni Edisona powstał pierwszy film pokazujący Inuitów zatytułowany Wioska Eskimosów (Esquimaux Village).

${ }^{6}$ M. Beaucage, Aboriginal Voices: Entitlement Through Storytelling, w: Mirror Machine: Video and Identity, red. J. Marchessault, YYZ Books, Toronto 1995, s. 214-226; L. Todd, Three Moments After Savage Graces, "Harbour” 1993, t. 9, s. 57-62; S. Niro, Artist's Statement: Watchful Eyes. Native American Women Artists, The Heard Museum, Phoenix 1994.

${ }^{7}$ H. K. Bhabha, Kwestia Innego. Stereotyp, dyskryminacja i dyskurs kolonializmu, w: tegoż, Miejsca kultury, tłum. T. Dobrogoszcz, Wydawnictwo Uniwersytetu Jagiellońskiego, Kraków 2010, s. 57.

${ }^{8}$ Tamże, s. 68.
${ }^{9}$ Por. K. Knopf, dz. cyt., s. 74-75.

${ }^{10}$ F. Ginsburg, Screen Memories: Resignifying the Traditional in Indigenous Media, w: Media Worlds: Anthropology on New Terrain, red. F. Ginsburg, L. Abu-Lughod, B. Larkin, University of California Press, Berkeley 2002, s. 40 .

${ }^{11}$ Dwa lata wcześniej, w 1966 r., zajmujący się komunikacją wizualną Sol Worth i antropolog John Adair rozpoczęli realizację projektu badawczego finansowanego przez National Science Foundation, w ramach którego grupa Indian Nawaho została wyposażona w kamery i kręciła krótkie filmy odzwierciedlające ich sposób patrzenia na świat. Wyniki badań wraz $\mathrm{z}$ analizą materiału wizualnego uczeni opublikowali w książce Through Navajo Eyes: An Exploration in Film Communication and Anthropology (1972). Amerykańscy naukowcy wykonali pierwszy krok w kierunku dekolonizacji spojrzenia, choć ich celem było jedynie znalezienie odpowiedzi na pytanie, w jaki sposób ludność rdzenna wykorzystuje nową technologię jako środek ekspresji kulturowej.

${ }^{12}$ Film można zobaczyć na stronie internetowej National Film Board: https://www.nfb.ca/playlists/aboriginal-voice-national-film-board/playback/\#7 (dostęp: 25.08.2020). W podobnej konwencji, z pierwszoplanową rolą muzyki (piosenkę śpiewał Bob Charlie), jest utrzymany kolejny film, Kim byli Pierwsi (Who Were the Ones, reż. Michael Mitchell, 1972, 7 min). Szczegółowe informacje na temat zrealizowanych wówczas filmów można znaleźć w artykule Michelle Stewart The Indian Film Crews of Challenge for Change: Representation and the State, "Canadian Journal of Film Studies" 2007, t. 16, nr 2, s. 49-81.

${ }^{13}$ Zob. https://www.nfb.ca/playlists/aboriginalvoice-national-film-board-/playback/\#3 (dostęp: 25.08.2020).

14 Por. M. Stewart, dz. cyt., s. 65.

${ }^{15}$ National Film Board jest organizacją powołaną do życia w 1939 r. przez rząd kanadyjski, stwo- 
rzoną i kierowaną przez dokumentalistę Johna Griersona.

${ }^{16}$ Zainteresowanych tematem kanadyjskich szkół $\mathrm{z}$ internatem odsyłam do znakomitego reportażu Joanny Gierak-Onoszko 27 śmierci Toby'ego Obeda, Wydawnictwo Dowody na Istnienie, Warszawa 2019.

17 Warto wspomnieć o wcześniejszym filmie tej reżyserki, który jest przykładem jej zaangażowania politycznego. Incydent w Restigouche (Incident at Restigouche, 1984, $46 \mathrm{~min}$ ) to zapis sporu o prawo do połowu pstrągów między urzędnikami państwowymi i służbami porządkowymi a członkami plemienia Mikmaków.

18 Por. J. L. Gauthier, Dismantling the Master's House: The Feminist Fourth Cinema. Documentaries of Alanis Obomsawin and Loretta Todd, w: Native Americans on Film Conversations... dz. cyt., s. 95-97.

${ }^{19}$ Interesujące odczytanie filmu Shelley Niro proponuje Kerstin Knopf w książce Decolonizing the Lens of Power, dz. cyt., s. 208-237.

${ }^{20} \mathrm{Na}$ temat związków filmu Niro z irokeską legendą piszą dwie badaczki: Miléna Santoro w artykule The Rise of First Nations' Fiction Films: Shelley Niro, Jeff Barnaby, and Yves Sioui Durand, "American Review of Canadian Studies" 2013, t. 43, nr 2, s. 271 oraz S. Monani, "Kissed by Lightning" and Fourth Cinema's Natureculture Continuum, w: Ecoambiguity, Community, and Development: Toward a Politicized Ecocriticism, red. S. Slovic, S. Rangarajan, V. Sarveswaran, Lexington Books, Lanham 2014, s. 131-148.

${ }^{21}$ K. Bertrand, Canadian Indigenous Cinema: From Alanis Obomsawin to the Wapikoni Mobile, w: The Oxford Handbook of Canadian Cinema, red. J. Marchessault, W. Straw, Oxford University Press, New York 2019, s. 107-108.

${ }^{22} \mathrm{Na}$ temat twórczości artystek związanych z Arnait Video Productions zob. artykuł napisany przez Cache Collective - grupę młodych badaczek z Queen's University w Kingston (prowincja Ontario): Lindsay Leitch, Erin Morton, Emily Rothwell, Taryn Sirove, Andreę Terry i Michelle Veitch. Zob. Cache Collective, Cache: Provisions and Productions in Contemporary Igloolik Video, w: Global Indigenous Media: Cultures, Poetics, and Politics, red. P. Wilson, M. Stewart, Duke University Press, Durham 2008, s. 74-88.

${ }^{23}$ Por. K. Bertrand, The Wapikoni Mobile and the Birth of a New Indigenous Cinema in Québec, "American Review of Canadian Studies" 2013, t. 43 , nr 2, s. 283-289.
${ }^{24}$ Por. S. Niro, S. Monani, Resistance and Hope in Mohawk Cinema: Iroquois Cosmologies and Histories, w: Ecocriticism and Indigenous Studies: Conversations from Earth to Cosmos, red. S. Monani, J. Adamson, Routledge, New York 2017, s. 154-156.

${ }^{25}$ Nie licząc urodzonego w Nowym Jorku Normana Cohna, wszyscy założyciele Igloolik Isuma Productions byli Inuitami. W latach 70. Cohn przyjechał na Wyspę Edwarda, gdzie powołał do życia Centre for Television Studies, realizował filmy o ludziach wykluczonych, sierotach, mieszkańcach domów opieki społecznej. Por. M. R. Evans, Isuma: Inuit Video Art, McGill-Queens University Press, Montreal - Kingston 2008, s. 70. W 2011 r. wytwórnia ogłosiła upadłość z powodów finansowych, a w jej miejsce powstała nowa firma, założona przez Kunuka i Cohna, o nazwie Kingulliit (Następne pokolenie).

${ }^{26}$ S. M. Huhndorf, Mapping the Americas: The Transnational Politics of Contemporary Native Culture, Cornell University Press, Ithaca 2009, s. $88-89$.

27 Por. M. Bohr, Cinema of Emancipation and Zacharias Kunuk's "Atanarjuat: The Fast Runner", w: Films on Ice: Cinemas of the Arctic, red. S. MacKenzie, A. Westerståhl Stenport, Edinburgh University Press, Edinburgh 2015, s. 88.

${ }^{28}$ Por. L. Bessire, Talking Back to Primitivism: Divided Audiences, Collective Desires, "American Anthropologist" 2003, t. 105, nr 4, s. 832-837.

${ }^{29}$ R. Schneider, Performing Remains: Art and War in Times of Theatrical Reenactment, Routledge, London 2011, s. 33.

${ }^{30}$ Por. M. Siebert, "Atanarjuat" and the Ideological Work of Indigenous Filmmaking, w: tejże, Indians Playing Indian: Multiculturalism and Contemporary Indigenous Art in North America, The University of Alabama Press, Tuscaloosa 2015, s. 68 .

31 S. R. Lyons, Rhetorical Sovereignty: What Do American Indians Want from Writing?, ", College Composition and Communication" 2000, t. 51, nr 3, s. 449.

${ }^{32}$ M. R. Evans, "The Fast Runner": Filming the Legend of Atanarjuat, University of Nebraska Press, Lincoln 2010, s. 1.

${ }^{33}$ Por. S. Jasen, The Archive and Reenactment: Performing Knowledge in the Making of "The Journals of Knud Rasmussen", "The Velvet Light Trap" 2013, nr 71, s. 4.

34 D. Taylor, Archiwum i repertuar. Performanse i performatywność. PerFORwhat studies?, tłum. M. Sugiera, M. Borowski, „Didaskalia” 2014, nr 120, s. 30. 
${ }^{35}$ Por. S. Jasen, dz. cyt., s. 8-9.

${ }^{36}$ Do pewnego stopnia twórczość artystów natywnych wpisuje się w pojęcie „wtórnej oralności”, zdefiniowane niegdyś przez Waltera J. Onga w książce Oralność i piśmienność. Słowo poddane technologii (tłum. J. Japola, Wydawnic- two Katolickiego Uniwersytetu Lubelskiego, Lublin 1992). Kanadyjski badacz posługuje się tym określeniem dla wskazania na wykorzystanie nowych środków przekazu, które przywracają znaczenie tradycyjnej wspólnocie i sytuują wiedzę w kontekście życia codziennego.

Krzysztof Loska

\section{Bibliografia}

Beaucage, M. (1995). Aboriginal Voices: Entitlement Through Storytelling. W: J. Marchessault (red.), Mirror Machine: Video and Identity (ss. 214-226). Toronto: YYZ Books.

Bertrand, K. (2013). The Wapikoni Mobile and the Birth of a New Indigenous Cinema in Québec. American Review of Canadian Studies, 43 (2), ss. 283-289. https://doi.org/10.1080/02722011.2013.795023

Bertrand, K. (2019). Canadian Indigenous Cinema: From Alanis Obomsawin to the Wapikoni Mobile. W: J. Marchessault, W. Straw (red.), The Oxford Handbook of Canadian Cinema (ss. 105-124). New York: Oxford University Press.

Bessire, L. (2003). Talking Back to Primitivism: Divided Audiences, Collective Desires. American Anthropologist, 105 (4), ss. 832-837. https://doi.org/10.1525/aa.2003.105.4.832

Bhabha, H. K. (2010). Miejsca kultury (thum. T. Dobrogoszcz). Kraków: Wydawnictwo Uniwersytetu Jagiellońskiego.

Bohr, M. (2015). Cinema of Emancipation and Zacharias Kunuk's „Atanarjuat: The Fast Runner”. W: S. MacKenzie, A. Westerståhl Stenport (red.), Films on Ice: Cinemas of the Arctic (ss. 84-96). Edinburgh: Edinburgh University Press.

Cache Collective (2008). Cache: Provisions and Productions in Contemporary Igloolik Video. W: P. Wilson, M. Stewart (red.), Global Indigenous Media: Cultures, Poetics, and Politics (ss. 74-88). Durham: Duke University Press. 
Evans, M. R. (2002). Hegemony and Discourse: Negotiating Cultural Relationships Through Media Production. fournalism: Theory, Practice \& Criticism, 3 (3), ss. 309-329. https://doi.org/10.1177/146488490200300302

Evans, M. R. (2008). Isuma: Inuit Video Art. Montreal - Kingston: McGill-Queens University Press.

Evans, M. R. (2010). „The Fast Runner”: Filming the Legend of Atanarjuat. Lincoln: University of Nebraska Press.

Gauthier, J. L. (2013). Dismantling the Master's House: The Feminist Fourth Cinema. Documentaries of Alanis Obomsawin and Loretta Todd. W: M. E. Marubbio, E. L. Buffalohead (red.), Native Americans on Film Conversations, Teaching, and Theory (ss. 89-115). Lexington: The University Press of Kentucky.

Gierak-Onoszko, J. (2019). 27 śmierci Toby'ego Obeda. Warszawa: Wydawnictwo Dowody na Istnienie.

Ginsburg, F. (1991). Indigenous Media: Faustian Contract or Global Village?. Cultural Anthropology, 6 (1), ss. 92-112. https://doi.org/10.1525/can.1991.6.1.02a0o040

Ginsburg, F. (2002). Screen Memories: Resignifying the Traditional in Indigenous Media. W: F. Ginsburg, L. Abu-Lughod, B. Larkin (red.), Media Worlds: Anthropology on New Terrain (ss. 39-57). Berkeley: University of California Press.

Huhndorf, S. M. (2009). Mapping the Americas: The Transnational Politics of Contemporary Native Culture. Ithaca: Cornell University Press.

Jasen, S. (2013). The Archive and Reenactment: Performing Knowledge in the Making of „The Journals of Knud Rasmussen”. The Velvet Light Trap, 71 (1), ss. 3-14. https://doi.org/10.7560/VLT7102

Knopf, K. (2008). Decolonizing the Lens of Power: Indigenous Films in North America. Amsterdam - New York: Editions Rodopi.

Lewis, R. (2006). Alanis Obomsawin: The Vision of a Native Filmmaker. Lincoln: University of Nebraska Press.

Lyons, S. R. (2000). Rhetorical Sovereignty: What Do American Indians Want from Writing?. College Composition and Communication, 51 (3), ss. 447-468. https://doi.org/10.2307/358744

Monani, S. (2014). „Kissed by Lightning” and Fourth Cinema's Natureculture Continuum. W: S. Slovic, S. Rangarajan, V. Sarveswaran (red.), Ecoambiguity, Community, and Development: Toward a Politicized Ecocriticism (ss. 131-148). Lanham: Lexington Books.

Niro, S. (1994). Artist's Statement: Watchful Eyes. Native American Women Artists. Phoenix: The Heard Museum.

Niro, S., Monani, S. (2017). Resistance and Hope in Mohawk Cinema: Iroquois Cosmologies and Histories. W: S. Monani, J. Adamson (red.), Ecocriticism and Indigenous Studies: Conversations from Earth to Cosmos (ss. 154-168). New York: Routledge.

Ong, W. J. (1992). Oralność i piśmienność. Stowo poddane technologii (tłum. J. Japola). Lublin: Wydawnictwo Katolickiego Uniwersytetu Lubelskiego.

Raheja, M. H. (2013). Reading Nanook's Smile: Visual Sovereignty, Indigenous Revisions of Ethnography, and „Atanarjuat: The Fast Runner”. W: M. E. Marubbio, E. L. Buffalohead (red.), Native Americans on Film Conversations, Teaching, and Theory (ss. 58-88). Lexington: The University Press of Kentucky.

Santoro, M. (2013). The Rise of First Nations' Fiction Films: Shelley Niro, Jeff Barnaby, and Yves Sioui Durand. American Review of Canadian Studies, 43 (2), ss. 267-282. https://doi.org/10.1080/02722011.2013.795031 
Schneider, R. (2011). Performing Remains: Art and War in Times of Theatrical Reenactment. London: Routledge.

Siebert, M. (2015). Indians Playing Indian: Multiculturalism and Contemporary Indigenous Art in North America. Tuscaloosa: The University of Alabama Press.

Stewart, M. (2007). The Indian Film Crews of Challenge for Change: Representation and the State. Canadian Fournal of Film Studies, $16 \quad$ (2), $5 s . \quad 49-81$. https://doi.org/10.3138/cjfs.16.2.49

Taylor, D. (2014). Archiwum i repertuar. Performanse i performatywność. PerFORwhat studies? (thum. M. Sugiera, M. Borowski). Didaskalia, (120), ss. 22-38.

Todd, L. (1993). Three Moments After Savage Graces. Harbour, 9, ss. 57-62.

Worth, S., Adair, J. (1972). Through Navajo Eyes: An Exploration in Film Communication and Anthropology. Bloomington: Indiana University Press.

Keywords:
indigenous media;
postcolonialism;
First Nations
in Canada;
film and audiovisual
technology

Abstract
Krzysztof Loska

From the Point of View of Indigenous Peoples: Film as a Tool of Decolonization in Canada

The paper focuses on how native artists in Canada use audiovisual technology. Their films are considered in the context of postcolonial theory as part of a larger process in which indigenous peoples take control of image production and representation (Kerstin Knopf). Assuming that the decolonization of the gaze is connected with the struggle for political recognition and regaining control over one's own life, it can be concluded that the indigenous artists quickly saw the benefits of Western technology and decided to take over the tools of the former colonizers in order to rewrite the history of their own peoples and tell it anew. By analyzing feature films and documentaries made by directors, primarily working for Isuma Productions, Wapikoni Mobile and Arnait Video Productions, one can clearly notice the importance of the search for stylistic means by which national minorities may express their unique point of view. Technology therefore is not seen as a threat to native culture, but as a chance to rebuild community ties. 